\title{
An Empirical Study on Internal Control and Earnings Management of China's Listed Companies Based on the Modified Jones Model
}

\author{
Yaohong Chen ${ }^{1,}$ a , Jiming $\mathrm{Li}^{1}{ }^{1, b},{ }^{*}$ and Yujia Wang ${ }^{1}$ \\ ${ }^{1}$ Business School, Zhejiang University City College, Hangzhou 310015, China. \\ aycmcyh@gmail.com, blijm@zucc.edu.cn
}

\begin{abstract}
One of the key issues in the study of internal control (IC) is whether IC can effectively constrain earnings management (EM) of listed companies. By using a sample of 425 companies listed in Shenzhen Stock Exchange 2013-2015, and employing the modified Jones model, this paper explores the effects of IC on EM in listed companies in China. The results show that there is a significant negative correlation between IC levels and EM levels, and the high quality internal control can reduce earnings management by both accounting choices and real activities. The study also finds that listed companies mainly manipulate earnings through financial indicators of operating income growth and asset-liability ratio, and IC weakness such as the disclosure of inaccurate and untrue financial information will lead to the occurrence of financial frauds.
\end{abstract}

Keywords: Internal control, earnings management, modified Jones model.

\section{Introduction}

Earnings management is playing an increasingly important role towards managing reported earnings. Constituting a high-quality internal control system has long been regarded as significant to secure high-quality financial reporting. This paper takes 425 companies listed on Shenzhen Stock Exchange in China as sample with the financial data of these companies during 2013-2015 and builds a scientific evaluation model based on the modified Jones model, in order to objectively discuss the correlation between internal control and earnings management and obtain valuable results.

\section{Literature Review}

\subsection{Negative Correlation between Internal Control and Earnings Management}

In recent years, the result of most scholars' research is that there is a negative correlation between internal control quality and earnings management. In particular, most studies have examined the effect of internal control quality on earnings management; while some literatures tend to study in more depth. Wang and Duane (2018) find that media attention and high-quality internal control can effectively inhibit the listed company's real earnings management behavior, and the inhibitory effects of the two have a substitution effect [1]. In contrast, some scholars' studies involve more specific and in-depth aspects. Ying (2016) discovers that the disclosure of internal control information can influence earnings management via agency cost, and the improvement of the disclosure of internal control information will effectively reduce agency cost, thus restricting earnings management [2]. Eatmon and Baroque (2015) find a significant negative relationship between earnings management and disclosure quality [3].

\subsection{No Correlation between Internal Control and Earnings Management}

Meanwhile, a comparable proportion of the research results show that there is no correlation between internal control quality and earnings management. Zhang (2011) finds that the improvement of internal control quality is not accompanied with earnings quality, while the company's intrinsic characteristics and governance factors will systematically affect the quality of internal control and earnings quality [4]. Ago (2014) finds that there is no inevitability between the two, and when a company has excellent internal control, its continuity of corporate earnings still cannot be guaranteed, but if the company's internal control is flawed, thus its earnings persistence is inconsistent [5]. 


\section{Methodology}

\subsection{Hypothesis}

In view of existing literatures, there is a negative correlation between internal control and earnings management. Accordingly, this paper proposes the following assumption:

$H_{0}$ : There is negative correlation between internal control and earnings management.

\subsection{Sample}

This paper chooses Shenzhen Stock Exchange listed companies as samples, selects relevant data between 2013 and 2015 from CSMAR Database, and removes some companies under the criteria: (1) ST, *ST, and companies listed on suspension; (2) SME board and GEM companies; (3) Financial insurance and real estate companies. We finally obtain 425 samples.

\subsection{Variables}

Internal control quality be ICQ: a standard internal control audit report is awarded 4; a nonstandard report with an emphasis of matter is awarded 3; a non-standard report with negative opinions is awarded 2; a report that cannot express opinions is awarded 1. If a company discloses its internal control self-evaluation report and issues an unqualified audit report, extra 1 will be added. Audit quality of an accounting firm (If the report is issued by the Big Four accounting firms, the value is 1; otherwise, the value is 0 ) be AUDIT.

\subsection{Model}

\subsubsection{Modified Jones Model}

$$
\begin{gathered}
\frac{T A_{t}}{A_{t-1}}=\beta_{1}\left(\frac{1}{A_{t-1}}\right)+\beta_{2}\left(\frac{\Delta R E V_{t}-\Delta R E C t}{A_{t-1}}\right)+\beta_{3}\left(\frac{P P E_{t}}{A_{t-1}}\right)+\varepsilon_{t} \\
\frac{N D A_{t}}{A_{t-1}}=\beta_{1}\left(\frac{1}{A_{t-1}}\right)+\beta_{2}\left(\frac{\Delta R E V_{t}-\Delta R E C t}{A_{t-1}}\right)+\beta_{3}\left(\frac{P P E_{t}}{A_{t-1}}\right) \\
\frac{D A_{t}}{A_{t-1}}=\frac{T A_{t}}{A_{t-1}}-\frac{N D A_{t}}{A_{t-1}}
\end{gathered}
$$

$T A_{t}$ represents a company's total accrued profit in year t; $\triangle R E V_{t}$ represents the change in the sales revenue for year $\mathrm{t} ; \triangle R E C_{t}$ refers to the change in the accounts receivables for year $\mathrm{t} ; \triangle P P E_{t}$ refers to the net fixed assets for year t. Using SPSS and formula (3-1) to (3-3), we obtain manipulative

\begin{tabular}{|c|c|c|c|c|c|}
\hline \multirow{2}{*}{ Model } & \multicolumn{2}{|c|}{ Unstd. Coeff. } & \multirow{2}{*}{$\begin{array}{c}\text { Std. Coeff. } \\
\text { Beta }\end{array}$} & \multirow{2}{*}{$t$-tests } & \multirow{2}{*}{ sig } \\
\hline & B & Std. Error & & & \\
\hline (Constants) & .035 & .016 & & 2.274 & .023 \\
\hline$\frac{1}{A_{t-1}}$ & 59824630.664 & 9821595.932 & .262 & 6.091 & .000 \\
\hline$\left(\frac{\Delta R E V_{t}-\Delta R E C t}{A_{t-1}}\right)$ & .200 & .040 & .230 & 5.055 & .000 \\
\hline$\frac{P P E_{t}}{A_{t-1}}$ & -.239 & .028 & -.390 & -8.560 & .000 \\
\hline
\end{tabular}
accruals.

Table 1. Coefficient Measurement

\subsubsection{Regression Model}

The multiple regression linear model is shown below:

$$
\begin{aligned}
& D A=\alpha_{0}+\alpha_{1} \times I C Q+\alpha_{2} \times R O E+\alpha_{3} \times R O R+\alpha_{4} \times D A R+\alpha_{5} \times L+\alpha_{6} \times B O D+ \\
& \alpha_{7} \times M+\alpha_{8} \times I D+\alpha_{9} \times B O S+\alpha_{10} \times A U D I T+\varepsilon
\end{aligned}
$$




\subsection{Results}

\subsubsection{Descriptive Results}

From description results, it can be seen that the maximum value of the absolute value of manipulative accruals is 4.2805 , indicating there is a huge gap in the degree of earnings management among different listed companies; additionally, the mean of DA is 0.099031 . Overall, the average degree of earnings management of Chinese listed companies is not very high. The mean value of internal control quality is high as 4.87 , which shows that for the entire market, the quality of internal control is acceptable. The average shareholding ratio indicated that the largest shareholders hold most of the company's equity, have a greater say, and can induce internal control to their own favorable direction in order to provide more opportunities for the implementation of earnings management practices; while the remaining minority shareholders are in a weak position.

Table 2. Correlation Analysis

\begin{tabular}{|c|c|c|c|c|c|c|c|c|c|c|c|c|}
\hline \multicolumn{2}{|c|}{ Variables } & $\mathrm{DA}$ & ICQ & ROE & ROR & DAR & $\mathrm{L}$ & B0D & $\mathrm{M}$ & ID & BOS & AUDIT \\
\hline \multirow{2}{*}{ DA } & PCC & 1 & -.096 & -.014 & .767 & -.055 & -.013 & -.015 & .033 & -.030 & -.069 & -.014 \\
\hline & $\alpha_{\text {test }}$ & & .048 & .770 & .000 & .261 & .797 & .752 & .497 & .533 & .157 & .778 \\
\hline \multirow{2}{*}{ ICQ } & PCC & -.096 & 1 & .041 & .003 & -.051 & .057 & .021 & .025 & .047 & .047 & .048 \\
\hline & $\alpha_{\text {test }}$ & .048 & & .400 & .954 & .298 & .240 & .661 & .606 & .333 & .337 & .324 \\
\hline \multirow{2}{*}{ ROE } & PCC & -.014 & .041 & 1 & .022 & -.026 & .039 & .046 & .003 & .002 & .008 & .066 \\
\hline & $\alpha_{\text {test }}$ & .770 & .400 & & .651 & .599 & .426 & .343 & .957 & .959 & .863 & .177 \\
\hline \multirow{2}{*}{ ROR } & PCC & .767 & .003 & .022 & 1 & -.033 & -.026 & -.009 & .059 & -.012 & -.080 & -.026 \\
\hline & $\alpha_{\text {test }}$ & .000 & .954 & .651 & & .493 & .590 & .857 & .225 & .805 & .101 & .590 \\
\hline \multirow{2}{*}{ DAR } & PCC & -.055 & -.051 & -.026 & -.033 & 1 & .104 & .088 & .212 & $.104 *$ & .051 & .026 \\
\hline & $\alpha_{\text {test }}$ & .261 & .298 & .599 & .493 & & .033 & .071 & .000 & .032 & .298 & .588 \\
\hline \multirow{2}{*}{$\mathrm{L}$} & PCC & -.013 & .057 & .039 & -.026 & .104 & 1 & .008 & -.009 & .014 & .109 & .074 \\
\hline & $\alpha_{\text {test }}$ & .797 & .240 & .426 & .590 & .033 & & .873 & .858 & .769 & .024 & .130 \\
\hline \multirow{2}{*}{ BOD } & PCC & -.015 & .021 & .046 & -.009 & .088 & .008 & 1 & .073 & .778 & .232 & .086 \\
\hline & $\alpha_{\text {test }}$ & .752 & .661 & .343 & .857 & .071 & .873 & & .135 & .000 & .000 & .078 \\
\hline \multirow{2}{*}{ M } & PCC & .033 & .025 & .003 & .059 & .212 & -.009 & .073 & 1 & .132 & -.016 & -.002 \\
\hline & $\alpha_{\text {test }}$ & .497 & .606 & .957 & .225 & .000 & .858 & .135 & & .006 & .743 & .974 \\
\hline \multirow{2}{*}{ ID } & PCC & -.030 & .047 & .002 & -.012 & .104 & .014 & .778 & .132 & 1 & .182 & .100 \\
\hline & $\alpha_{\text {test }}$ & .533 & .333 & .959 & .805 & .032 & .769 & .000 & .006 & & .000 & .040 \\
\hline \multirow{2}{*}{ BOS } & PCC & -.069 & .047 & .008 & -.080 & .051 & .109 & .232 & -.016 & .182 & 1 & .109 \\
\hline & $\alpha_{\text {test }}$ & .157 & .337 & .863 & .101 & .298 & .024 & .000 & .743 & .000 & & .024 \\
\hline \multirow{2}{*}{ AUDIT } & PCC & -.014 & .048 & .066 & -.026 & .026 & .074 & .086 & -.002 & $.100 *$ & .109 & 1 \\
\hline & $\alpha_{\text {test }}$ & .778 & .324 & .177 & .590 & .588 & .130 & .078 & .974 & .040 & .024 & \\
\hline
\end{tabular}

Notes: significant at 0.05 level (2-tailed); PCC represents Pearson Correlation Coefficient.

\subsubsection{Correlation Analysis}

We first do Pearson Correlation Test on dependent variables, independent variables and control variables. If the calculated probability is smaller than 0.025 , this indicates the existence of correlation between variables; if the probability is larger than 0.025 , this means that there is no relationship between variables. According to Table 4-1, the significance levels of both dependent variable DA and independent variable ICQ are greater than 0.025, showing there is no significant correlation between the two. In addition, levels of significance of other variables are mainly greater than 0.025 , indicating that there is no significant correlation between these variables.

\subsubsection{Regression Analysis}

From Table 4-2, the significance level of internal control quality ICQ is less than 0.025 , which shows the significant correlation between the internal control quality ICO and the manipulative accruals DA. In the regression model, the coefficient of internal control is -0.064 , showing that there 
is a significant negative correlation between the quality of internal control and the manipulative accruals. Hence, we reject the alternative hypothesis and accept the null hypothesis.

Similarly, the correlations between ROR and DA, and DAR and DA are significant. ROE, L, BOD, and AUDIT are all positively correlated, but their relationship with DA are not significant. Besides, there is a negative correlation between ID and BOS, but their relationships with DA are not significant, either. Therefore, there is no evidence shows that above variables affect earnings management. Consequently, they should not appear as control variables in the equation.

Table 3. Regression Analysis

\begin{tabular}{cccccc}
\hline \multirow{2}{*}{ Model } & \multicolumn{2}{c}{ Unstd. Coeff. } & Std. Coeff. & \multirow{2}{*}{-tests } & \multirow{2}{*}{ sig } \\
\cline { 2 - 4 } & $\mathrm{B}$ & Std. Coeff. & Beta & & \\
\hline (Constants) & .412 & .106 & & -885 & .000 \\
ICQ & -.064 & .020 & -.099 & -3.175 & .002 \\
ROE & -.026 & .027 & -.030 & -.973 & .331 \\
ROR & .135 & .005 & .767 & 24.548 & .000 \\
DAR & .040 & .036 & .036 & 1.110 & .026 \\
L & .027 & .047 & .018 & .562 & .574 \\
BOD & .002 & .006 & .021 & .412 & .681 \\
M & $2.217 \mathrm{E}-5$ & .002 & .000 & .014 & .989 \\
ID & -.011 & .018 & -.030 & -.595 & .552 \\
BOS & -.001 & .006 & -.004 & -.120 & .905 \\
AUDIT & .014 & .030 & .014 & .457 & .648 \\
\hline
\end{tabular}

\section{Conclusion and Discussion}

This paper empirically explored the impact of internal control quality on earnings management and managed to prove that internal control quality had a negative effect on earnings management, by analyzing the financial data of the sample of 425 listed companies in Shenzhen based on the modified Jones model. The results are as follows:

a. There is a negative correlation between the quality of internal control of listed companies and earnings management practices. High-quality internal control can effectively inhibit the occurrence of earnings management behavior;

b. In order to maintain their continuing operating performance and their ability to operate at a higher level, and attract more investors, enterprises with higher operating income growth rates and asset-liability ratios tend to whitewash their financial statement data, such as modifying operating profit, thus implement earnings management practices.

One limitation of the study is that the selection of control variables is not very appropriate. Other aspects of enterprises such as executive compensation should also be included.

\section{References}

[1]. Wang, L. J. \& Duane, W. T. The substitution effect of media concerns and internal control on real earnings management. Journal of Industrial Technological Economics, Vol.3 (2018), p. 8796.

[2]. Ying, Y. C. Internal control information disclosure quality, agency cost and earnings management-based on the empirical data from 2011 to 2013. Modern Economy, Vol. 7 (2016) No. 1, p. 1-52.

[3]. Eatmon, N. \& Baroque, O. A. Exploring the impact of internal corporate governance on the relation between disclosure quality and earnings management in the UK listed companies. Journal of Business Ethics, Vol. 18 (2015) No. 13, p.1-23. 
[4]. Zhang, G. Q. Internal control and earnings management--based on the empirical evidence of study on Chinese a-share companies in 2007. Economic Management, Vol. 30 (2008) No. 23-24, p. 112-119.

[5]. Gaol, R. Z. Study on the relationship between internal control quality and earnings management sustainability. Science Technology and Industry, Vol. 14 (2014) No. 8, p. 111-116. 